\title{
Supplementary Information for Recapture of the Non-Valence Excess Electron into the Excited Valence Orbital Leads to the Chemical Bond Cleavage in the Anion
}

Do Hyung Kang ${ }^{1}$, Jinwoo Kim ${ }^{1}$ and Sang Kyu Kim ${ }^{1 *}$

${ }^{1}$ Department of Chemistry, KAIST, Daejeon 34141, Republic of Korea

*Corresponding Author: sangkyukim@kaist.ac.kr 


\section{Time-resolved Photoelectron Imaging (TR-PEI) of 4-XPhO- DBS}

(a)

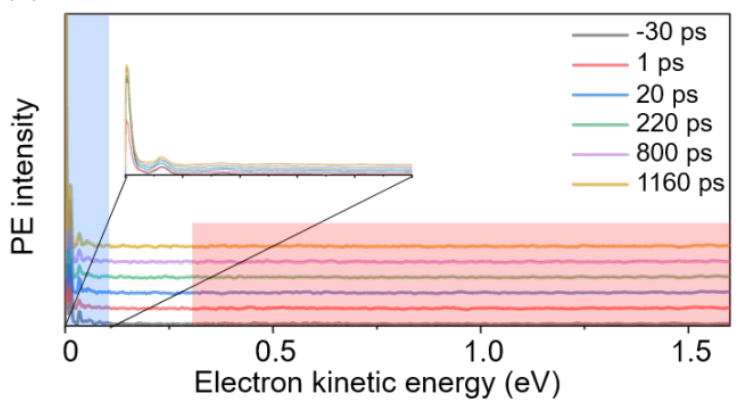

(b)

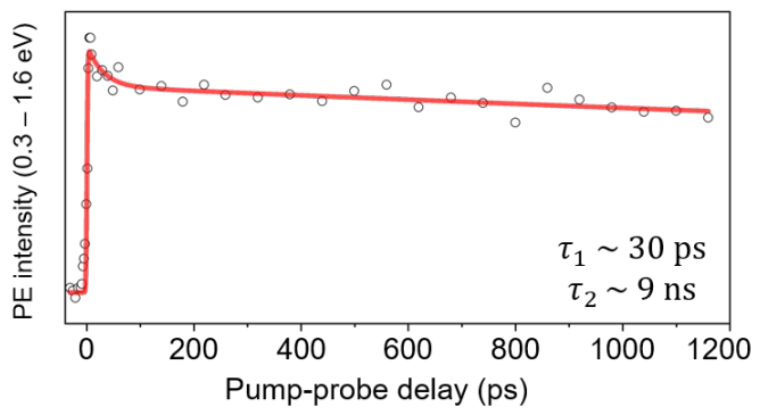

(c)

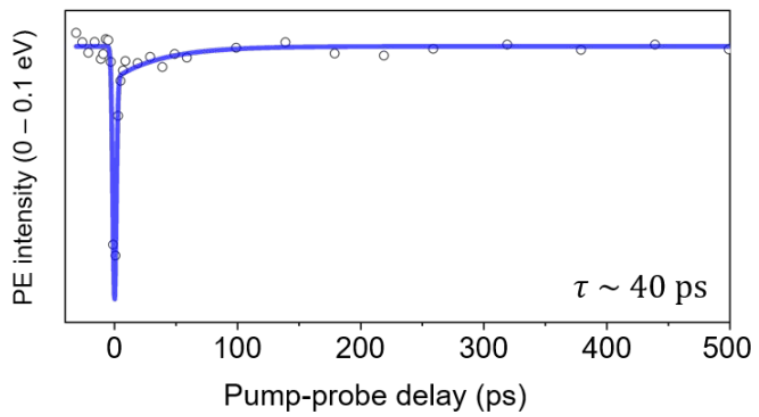

(d)

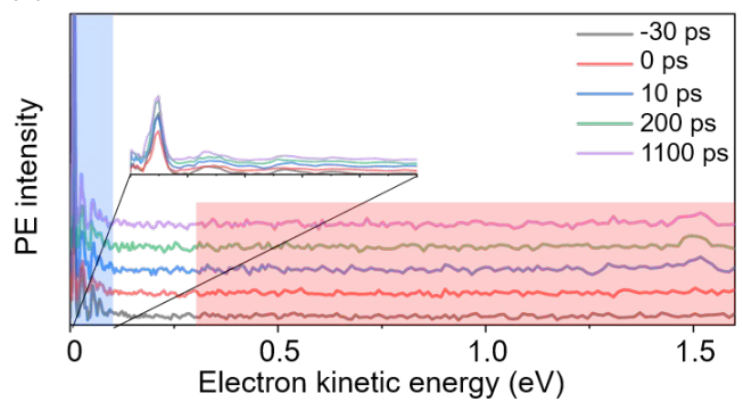

(e)

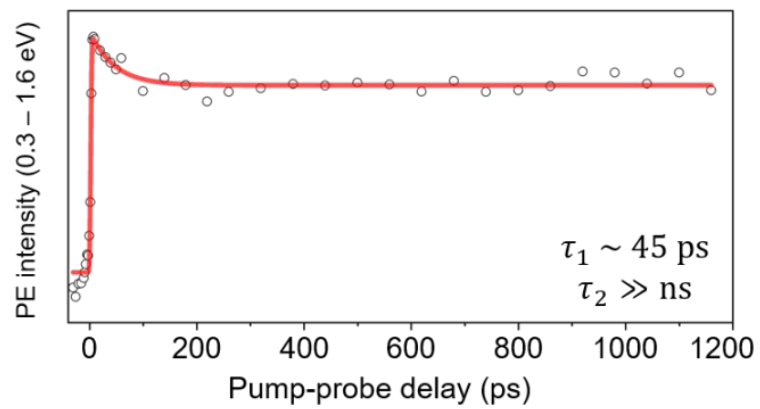

(f)

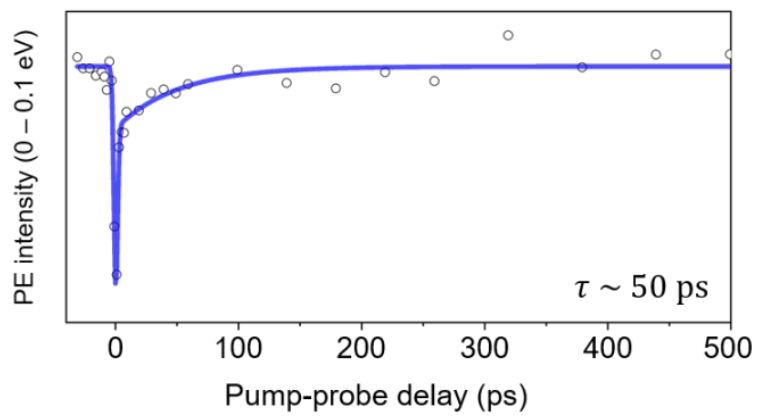

Figure S1. Picosecond TR-PEI of the zero-point level of the (a-c) 4-ClPhO- DBS and (d-f) 4-BrPhO- $\mathrm{DBS}^{-}$ $(\mathrm{a}, \mathrm{d})$ Photoelectron spectra in selected pump-probe delays. The low-kinetic energy region spectra $(0-$ $0.1 \mathrm{eV}$ ) are enlarged in insets. (b-e) Photoelectron transients of the high-kinetic energy region by integrating over the $0.3-1.6 \mathrm{eV}$ region. The photoelectron transients were fitted by bi-exponential decay functions. (c-f) Photoelectron transients of the low-kinetic energy region by integrating over the $0-0.1 \mathrm{eV}$ region. Single-exponential decay (recovery) functions were used for the fitting. 
(a)

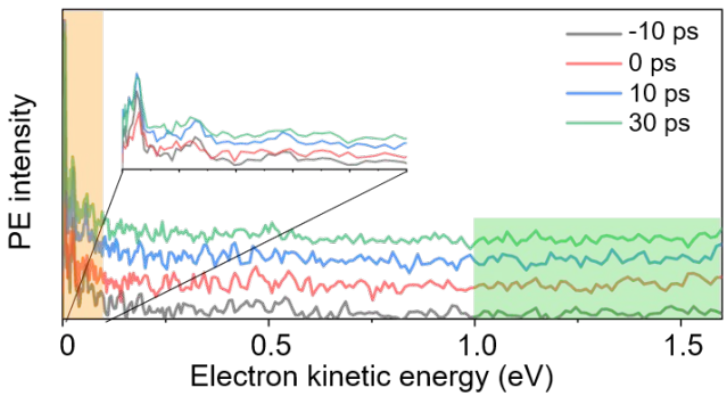

(b)

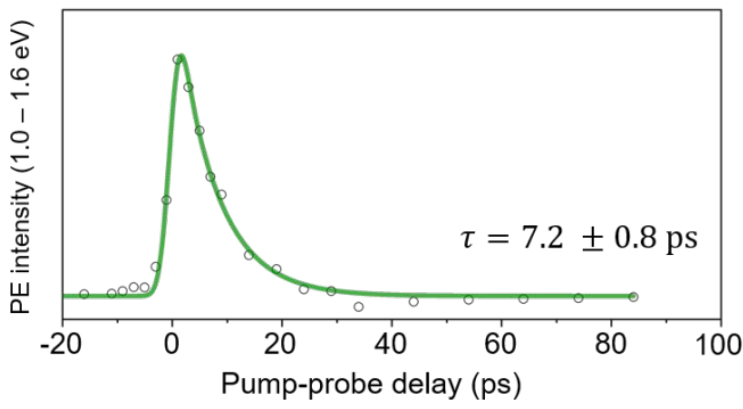

(c)

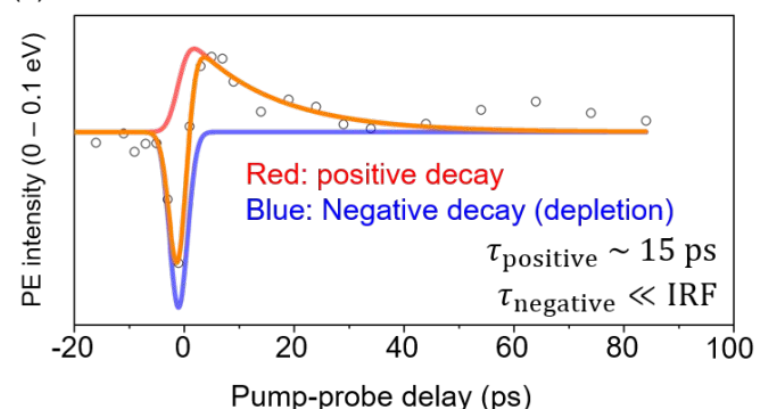

(d)

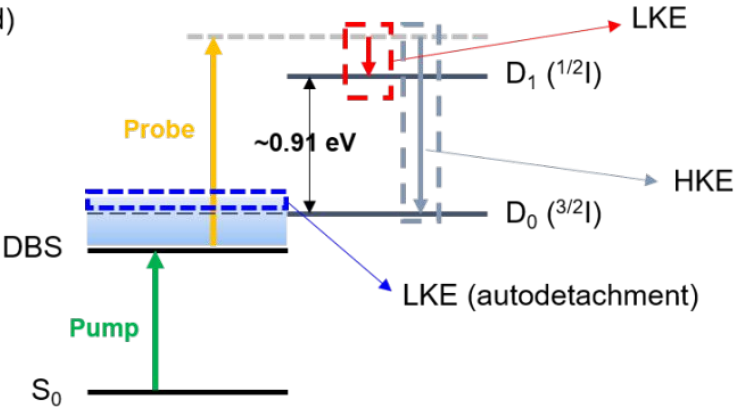

Figure S2. Picosecond TR-PEI of the zero-point level of the 4-IPhO- DBS. (a) Photoelectron spectra in selected pump-probe delays. The low-kinetic energy region spectra $(0-0.1 \mathrm{eV})$ is enlarged in inset. (b) Photoelectron transients of the high-kinetic energy region by integrating over the $1.0-1.6 \mathrm{eV}$ region. The photoelectron transients were fitted by a single-exponential decay function. (c) Photoelectron transients of the low-kinetic energy region by integrating over the $0-0.1 \mathrm{eV}$ region. Two singleexponential decay functions with opposite signs were used for the fitting. The positive decay function (red) represents the low-kinetic energy emission into the radical excited state $\left(D_{1}\right)$ located at the $\sim 0.91$ $\mathrm{eV}$ above the electron affinity (EA) by the probe pulse $(\sim 1.57 \mathrm{eV})$. Negative decay function (depletion, blue) represents the autodetachment signal from the ro-vibrationally hot DBS state. (d) Energetic diagram of the low-kinetic energy electron emission processes of the 4-IPhO-. Two low-kinetic energy electron emission processes through the autodetachment (blue) and direct detachment to the first electronically excited neutral state (red) are denoted. 


\section{Thermodynamic Calculation of the Dissociation Channels}

Asymptotic energy level of the dissociation product channels could be calculated by the electron affinities (EA) of the fragment atoms (X) or co-fragment $\mathrm{PhO}(-\mathrm{H}) \bullet$ radical and bond dissociation energies (BDE) of the $\mathrm{X}-\mathrm{PhO}$ bond. For the production of the halogen anionic fragment $\left(\mathrm{X}^{-}\right)$channel, energy difference upon the dissociation reaction is calculated as followings;

$\mathrm{X}+\mathrm{e}^{-} \rightarrow \mathrm{X}^{-}$

$4-\mathrm{XPhO} \rightarrow \mathrm{X}+\mathrm{PhO}(-\mathrm{H}) \bullet$

4-XPhO+e ${ }^{-} \rightarrow \mathrm{X}^{-}+\mathrm{PhO}(-\mathrm{H}) \bullet$
$\Delta \mathrm{E}=-\mathrm{EA}(\mathrm{X})$

$\Delta \mathrm{E}=\mathrm{BDE}(\mathrm{X}-\mathrm{PhO})$

$\Delta \mathrm{E}=\mathrm{D}_{0}(\mathrm{X}-\mathrm{PhO})-\mathrm{EA}(\mathrm{X})$
$(1)+(2)=(3)$

The EA of the halogen atoms are 295,324 , and $348 \mathrm{~kJ} / \mathrm{mol}$ for the iodine, bromine and chlorine, respectively. Bond dissociation energy of the $\mathrm{X}-\mathrm{PhO}$ bond was approximately referred from the iodobenzene $(268 \mathrm{~kJ} / \mathrm{mol})$, bromobenzene (337 $\mathrm{kJ} / \mathrm{mol})$, and chlorobenzene $(405 \mathrm{~kJ} / \mathrm{mol})$.

Alternatively, the halogen atom and anionic co-fragment production channel was calculated using the EA of the $\mathrm{PhO}(-\mathrm{H}) \bullet$ radical product. The $\mathrm{EA}$ of $\mathrm{PhO}(-\mathrm{H})$ was evaluated from the DFT calculation using Gaussian 09 packages at the B3LYP/def2TVZP level of theory. The thermodynamic equation and energy difference during the reaction could be calculated as followings;

$$
\begin{array}{ll}
\mathrm{PhO}(-\mathrm{H}) \bullet+\mathrm{e}^{-} \rightarrow \mathrm{PhO}(-\mathrm{H})^{-} & \Delta \mathrm{E}=-\mathrm{EA}(\mathrm{PhO}(-\mathrm{H})) \\
4-\mathrm{XPhO} \rightarrow \mathrm{X}+\mathrm{PhO}(-\mathrm{H}) \bullet & \Delta \mathrm{E}=\mathrm{BDE}(\mathrm{X}-\mathrm{PhO})
\end{array}
$$$$
4-\mathrm{XPhO}+\mathrm{e}^{-} \rightarrow \mathrm{X}+\mathrm{PhO}(-\mathrm{H})^{-}
$$

$\Delta E=\mathrm{D}_{0}(\mathrm{X}-\mathrm{PhO})-\mathrm{EA}(\mathrm{PhO}(-\mathrm{H}))(4)+(5)=(6)$ 
3. TD-DFT Calculation of the 4-ClPhO- and 4-BrPhO-

(a) 4-CIPhO-

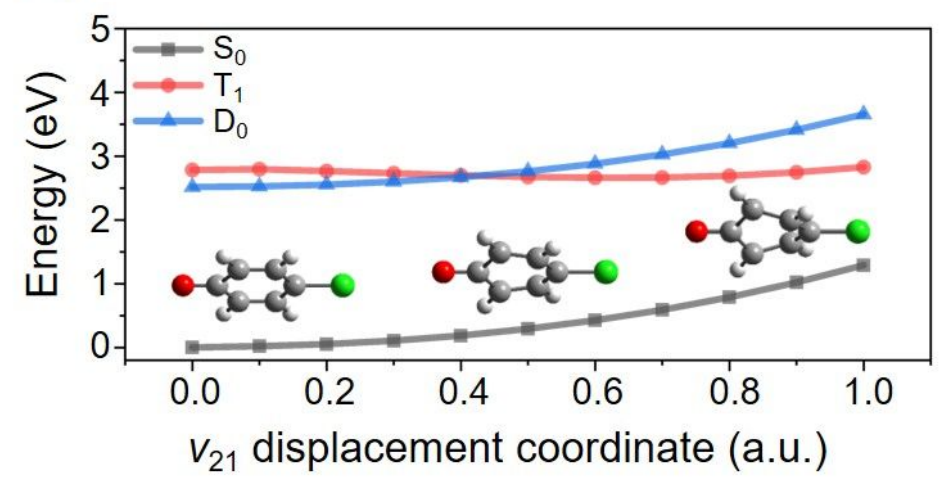

(b) $4-\mathrm{BrPhO}^{-}$

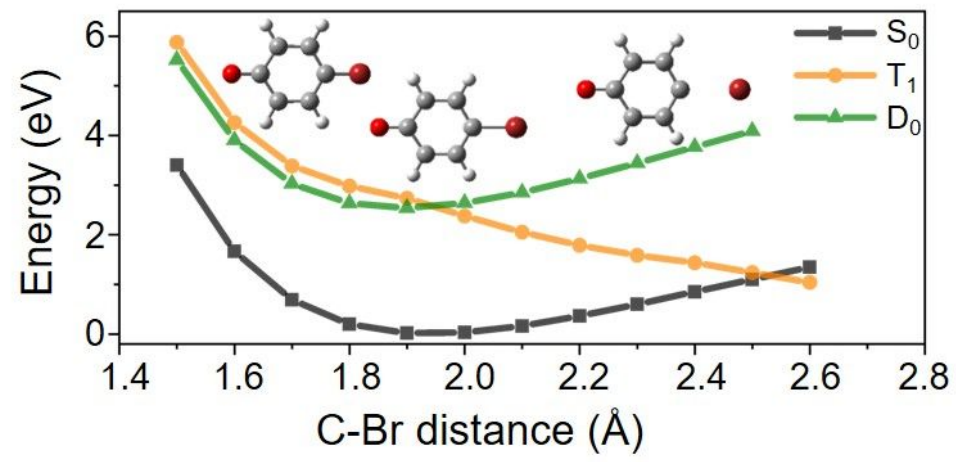

Figure S3. (a) Potential energy curve of the $4-\mathrm{ClPhO}^{-}$anionic ground state $\left(\mathrm{S}_{0}\right.$, grey), the first excited triplet state $\left(\mathrm{T}_{1}, \mathrm{red}\right)$, and neutral radical ground state $\left(\mathrm{D}_{0}\right.$, blue) along the $v_{21}$ displacement coordinate. (b) Potential energy curve of the $4-\mathrm{BrPhO}^{-}$anionic ground state $\left(\mathrm{S}_{0}\right.$, black), the first excited triplet state $\left(\mathrm{T}_{1}\right.$, yellow), and neutral radical ground state $\left(\mathrm{D}_{0}\right.$, green) along the $\mathrm{C}-\mathrm{Br}$ elongation coordinate. 
4. Resonant Photoelectron Spectra at the Zero-point Level of the 4-ClPhO-DBS

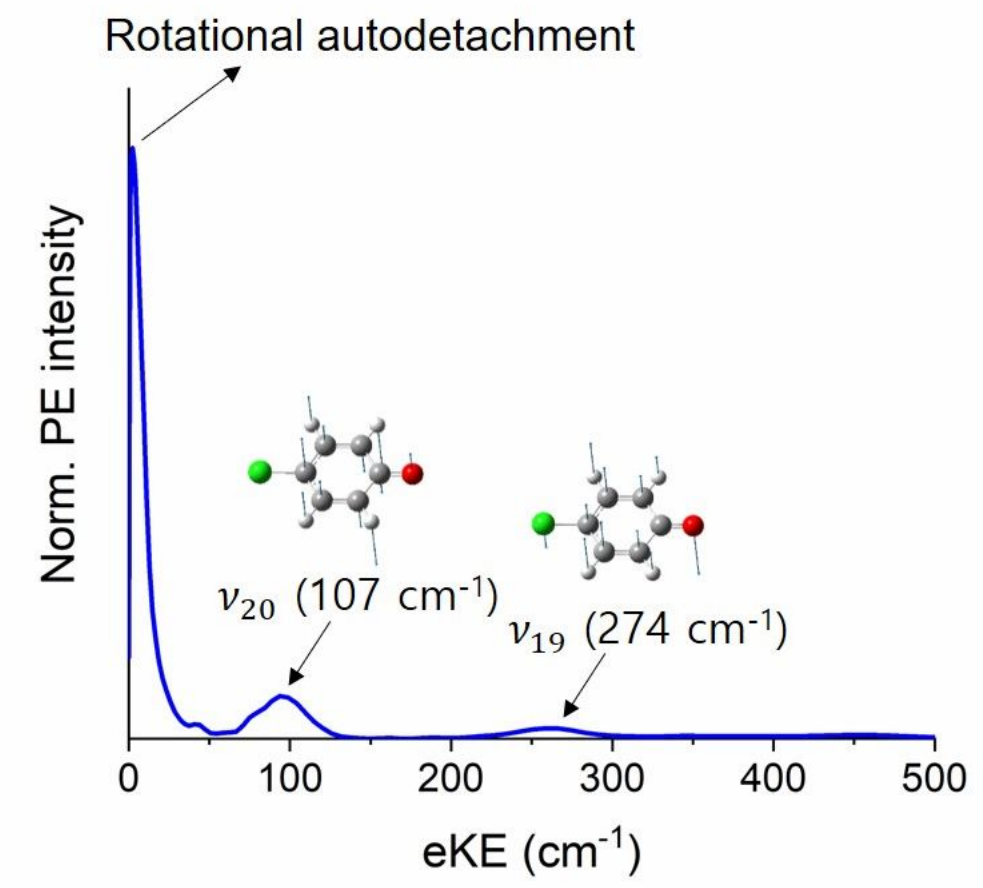

Figure S4. One-color resonant photoelectron imaging on the vibrational ground state of DBS of the 4-ClPhO-. At the zero-electron kinetic energy, a Boltzmann -like peak was revealed, which may be corresponding to the rotational autodetachment. Two minor peaks were also revealed at $100 \mathrm{~cm}^{-1}$ and $\sim 270 \mathrm{~cm}^{-1}$. The two lowest vibrational modes $\left(v_{20}=107 \mathrm{~cm}^{-1}\right.$ and $v_{19}=274$ $\mathrm{cm}^{-1}$ ) seem to be responsible for the both peaks, detached through the vibrational autodetachment process. 


\section{Calculation of the Rotational Autodetachment Ratio}

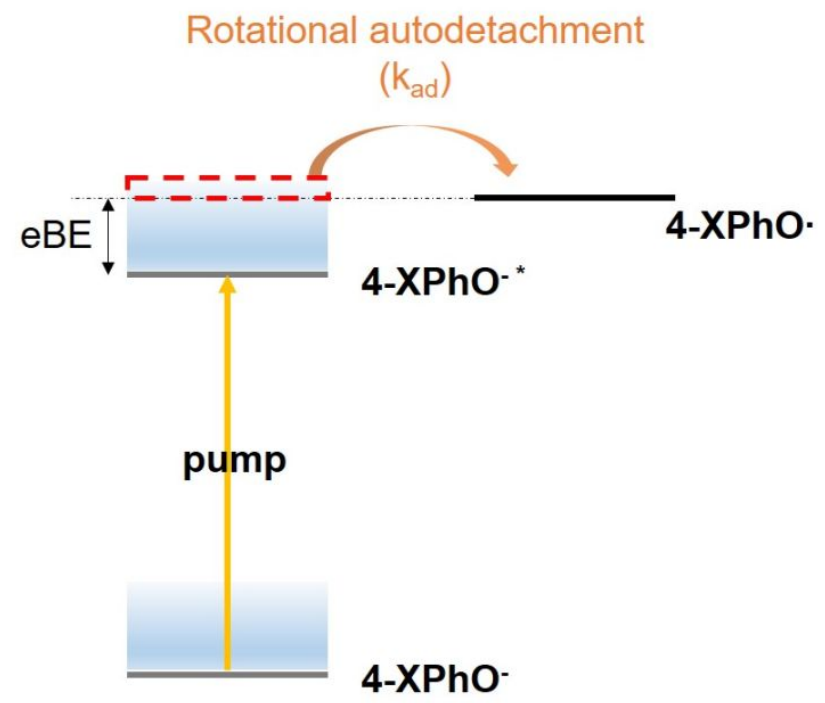

Figure S5. Schematic diagram of the rotational autodetachment at the vibrational ground state of DBS in the rotationally hot ensemble. Few portion of rotational ensemble that exceeds the DBS (red dashed box) is subject to the rotational autodetachment.

The ratio of the rotational ensemble exceeding the electron binding energy (eBE) of DBS was calculated. The rotational Boltzmann distribution could be described as:

$$
\frac{\mathrm{N}_{\mathrm{J}}}{\mathrm{N}_{0}}=\exp \left\{-\frac{\mathrm{B}\left(\mathrm{cm}^{-1}\right) \mathrm{hcJ}(\mathrm{J}+1)}{\mathrm{k}_{\mathrm{B}} \mathrm{T}}\right\}
$$

,where $\mathrm{N}_{\mathrm{J}}$ is the number of the state in J-th quantum number, $\mathrm{N}_{0}$ is the number of the state in $\mathrm{J}=0, \mathrm{~B}$ is the rotational constant in wavenumber, and $\mathrm{T}$ is the rotational temperature. From this equation and rotational constant exerting the largest perturbation on the DB orbit, B, we calculated the ratio of the state for each molecule that exceeding eBE of the DBS $\left(\mathrm{J}_{\min }\right.$, see Table.2). The ratio of the rotational ensemble that exceeding the eBE was calculated as:

$$
\text { Ratio }=\frac{\int_{J_{\min }}^{\inf } \exp \left\{-\mathrm{B}\left(\mathrm{cm}^{-1}\right) \mathrm{hcJ}(J+1) / \mathrm{k}_{\mathrm{B}} \mathrm{T}\right\} \mathrm{dJ}}{\int_{0}^{\inf } \exp \left\{-\mathrm{B}\left(\mathrm{cm}^{-1}\right) \mathrm{hcJ}(J+1) / \mathrm{k}_{\mathrm{B}} \mathrm{T}\right\} \mathrm{dJ}}
$$

,where $\mathrm{J}_{\min }$ is the minimum $\mathrm{J}$ quantum number that exceeding the eBE of each molecule; 


$$
\mathrm{eBE} \leq \mathrm{E}(\mathrm{rot})=\mathrm{BJ}_{\min }\left(\mathrm{J}_{\min }+1\right)
$$

Table S1. Calculated rotational constants of PhO- and 4-XPhO- anions and $\mathrm{J}_{\min }$ and ratios that exceed the electron binding energies (eBE) of each DBS of anion.

\begin{tabular}{c|c|ccc}
\hline & $\mathrm{eBE}\left(\mathrm{cm}^{-1}\right)^{\mathrm{a}}$ & Rot Const $\left(\mathrm{B}, \mathrm{cm}^{-1}\right)$ & $\mathrm{J}_{\min }$ & Ratio \\
\hline $\mathrm{PhO}^{-}$ & 97 & 0.0895 & 33 & $0.4 \%$ \\
$4-\mathrm{IPhO}^{-}$ & 53 & 0.0158 & 58 & $3.6 \%$ \\
$4-\mathrm{BrPhO}^{-}$ & 24 & 0.0211 & 34 & $15.4 \%$ \\
$4-\mathrm{ClPhO}^{-}$ & 11 & 0.0324 & 18 & $34.7 \%$ \\
\hline
\end{tabular}

${ }^{a}$ Experimental eBEs were measured in previous nanosecond photoelectron spectra in Ref.36 and Ref.38. 